\title{
Surface Acoustic Wave Nebulization Produces lons with Lower Internal Energy than Electrospray Ionization
}

\author{
Yue Huang, ${ }^{1}$ Sung Hwan Yoon, ${ }^{2}$ Scott R. Heron, ${ }^{2}$ Christophe D. Masselon, ${ }^{2,3}$ \\ J. Scott Edgar, ${ }^{2}$ František Tureček, ${ }^{1}$ David R. Goodlett ${ }^{2}$ \\ ${ }^{1}$ Department of Chemistry, University of Washington, Seattle, WA 98195-1700, USA \\ ${ }^{2}$ Department of Medicinal Chemistry, University of Washington, Seattle, WA 98195-1700, USA \\ ${ }^{3}$ Commissariat à l'Énergie Atomique, Grenoble, France
}

\begin{abstract}
Surface acoustic wave nebulization (SAWN) has recently been reported as a novel method to transfer non-volatile analytes directly from solution to the gas phase for mass spectrometric analysis. Here we present a comparison of the survival yield of SAWN versus electrospray ionization (ESI) produced ions. A series of substituted benzylpyridinium (BzPy) compounds were utilized to measure ion survival yield from which ion energetics were inferred. We also estimated bond dissociation energies using higher level quantum chemical calculations than previously reported for BzPy ions. Additionally, the effects on BzPy precursor ion survival of SAWN operational parameters such as inlet capillary temperature and solution flow-rate were investigated. Under all conditions tested, SAWN-generated BzPy ions displayed a higher tendency for survival and thus have lower internal energies than those formed by ESI.
\end{abstract}

Key words: Surface acoustic wave nebulization, Internal energy, Ionization method, ESI

\section{Introduction}

$\mathrm{E}$ lectrospray ionization (ESI) [1] and matrix-assisted laser desorption/ionization (MALDI) [2, 3] have gained widespread use due to their low internal energy distribution (i.e., softness) and ease of integration with sample handling and chromatographic techniques (LC-MS). These two ionization methods significantly contributed to the large growth in biological mass spectrometry (MS) in the last 20 years [4]. In addition to allowing large biomolecules to be ionized with minimal fragmentation, one popular application for both MALDI and ESI has been to make gas-phase

Electronic supplementary material The online version of this article (doi:10.1007/s13361-012-0352-8) contains supplementary material, which is available to authorized users.

Correspondence to: David Goodlett; e-mail: goodlett@uw.edu measurements of interactions between binding partners in noncovalent complexes. This native MS field has seen growth in the last few years [5-8] but remains difficult to practice due to the requirement to form ions without breaking noncovalent bonds. Thus, ionization methods that minimize energy transfer to an analyte are of interest.

Originally developed for the electronics industry, surface acoustic wave (SAW) technology has been utilized in various ways to manipulate fluids and as a microchip biosensor platform [9-12]. Recently, we have shown that the SAW technology could be used to nebulize samples from a planar piezoelectric substrate, and that these ions could then be analyzed by MS [13]. The SAW nebulization (SAWN) MS process combines the performance characteristics of ESI, namely production of multiply charged ions, with the ease of use of a planar device like in MALDI. In our initial report, a peptide solution was nebulized by SAW demonstrating the feasibility of detecting ions by MS. 
Another recent report demonstrated that SAWN can also be coupled with paper-based sample delivery [14]. In both cases, the application of a SAW leads to disruption of liquid surface tension in the droplet on the chip from which an aerosol forms. As we showed originally [13], this nebulized liquid contains solvated ions that enter the MS orifice due to local gas dynamics (Figure 1) where desolvation occurs, and MS and tandem MS experiments may be conducted.

Since SAWN is a relatively new method and because of recent interest in ambient ionization methods [15], we designed experiments to establish the operational figures of merit. Specifically, we report on an examination of the internal energy deposition in SAWN-produced ions by measuring ion survival yield of a series of substituted benzylpyridinium (BzPy) ions and compare these results to a parallel study with ESI. The BzPy ions are commonly referred to as "thermometer ions" because they have simple fragmentation patterns, and the relative intensities of nondissociating and fragment ions allow one to estimate the distribution of internal energy as a result of ionization or activation [16, 17]. The mean internal energies deposited during ionization are estimated on the basis of known BzPy $\mathrm{C}-\mathrm{N}$ bond dissociation energies that are presumed to represent the energy thresholds for the precursor ion dissociations. Fragmentation by bond cleavage between the benzyl and pyridinium moieties occurs for all substituted BzPy ions. Thus, a typical mass spectrum for a substituted BzPy ion contains two peaks, one for the precursor ion and one for the main fragment ion due to the loss of pyridine [18]. The corresponding ion dissociation energetics of BzPy ions have been mainly obtained by electronic structure calculations of varying quality and used as a reference to estimate the internal energy of conventional ionization methods, such as MALDI [19, 20], ESI [16, 21], desorption electrospray ionization (DESI) [22], direct analysis in real time (DART) [23], and silicon nanoparticle-assisted laser desorption/ionization (SPALDI) [24]. Here we employ new, higher-level, quantum chemical calculations to compare the internal energy of BzPy ions generated by SAWN and ESI. We show that under all conditions tested, SAWN-generated ions displayed a tendency for higher survival of BzPy precursor ions and thus lower internal energies than those formed by ESI.

\section{Experimental}

\section{SAWN Chip Fabrication and Operation}

The fabrication and operation of SAWN chips have been reported in detail elsewhere [13]. Briefly, a 128 Y-cut Xpropagating $3 \mathrm{in} . \mathrm{LiNbO}_{3}$ wafer was used as a substrate to pattern a SAW transducer (Crystal Technology, Inc., Palo Alto, CA, USA). SAWN electrodes were patterned using a chrome mask made with a Heidelberg $\mu$ PG 101 Laser Pattern Generator (Heidelberg Instruments Mikrotechnik $\mathrm{GmbH}$, Heidelberg, Germany) at the University of Washington Nanotech User Facility. Each device was made up of 20 pairs of $100 \mu \mathrm{m}$ interdigitated (IDT) electrodes (40 in total) with $100 \mu \mathrm{m}$ spacing and $10 \mathrm{~mm}$ aperture. Additionally, an electrode was patterned in the SAWN transducer activation area to allow the application of an external voltage to droplets or to ground the sample.

Specifically, SAWN chips were constructed using AZ 1512 positive photoresist (AZ Electronic Materials, Somerville, NJ, USA) spun onto the $\mathrm{LiNbO}_{3}$ wafer at $4000 \mathrm{rpm}$ for $30 \mathrm{~s}$, creating a $1-1.2 \mu \mathrm{m}$ thick sacrificial layer. This wafer was exposed using an Oriel mask aligner (Newport Corporation, Irvine, CA, USA) for $5 \mathrm{~s}$ and subsequently developed for $60 \mathrm{~s}$ in AZ 351 developer (AZ Electronic Materials). IDT microelectrodes were produced by heated vapor deposition of a $20 \mathrm{~nm}$ chrome adhesion layer followed by a $60 \mathrm{~nm}$ layer of gold. Lift off was performed in acetone (for $30 \mathrm{~min}$ ) to realize the electrode arrays for the SAW transducers. The operating frequency of the transducer used in this study was $9.56 \mathrm{MHz}$. A MXG analog signal generator (Agilent N5181A, Santa Clara, CA, USA) and a Mini Circuits ZHL-5 W-1, 5-500 MHz
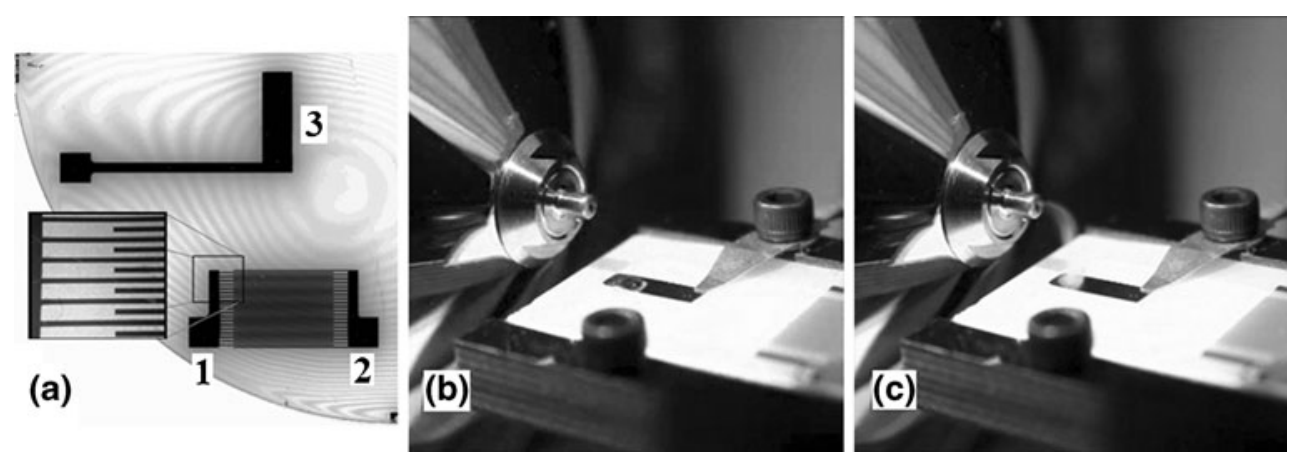

Figure 1. Surface acoustic wave nebulization (SAWN) chip and process. (a) Configuration of electrodes on the SAWN chip where gold nanolayer electrodes 1 and 2 of the interdigitated transducer (IDT) are connected to a signal generator through a copper pin [shown (b) and (c)] to produce a SAW, electrode 3, which is used to ground the chip surface and sample droplet. (b) Coupling SAWN with an atmospheric pressure ionization (API) inlet mass spectrometer where a drop of liquid is visible prior to SAW activation. (c) A plume of nebulized liquid is shown entering the API MS instrument post SAW activation 
amplifier (GwInstek GPS-2303; New York, NY) were used to activate the SAWN chip.

\section{Mass Spectrometry}

Experiments were carried out on an LTQ instrument (Thermo Scientific, San Jose, CA, USA). Both ESI and SAWN sources were mounted on the same instrument with identical mass spectrometer settings. The atmospheric pressure ionization (API) inlet capillary voltage was maintained at $20 \mathrm{~V}$ and the tube lens was set to $110 \mathrm{~V}$ for all experiments. A Thermo Scientific IonMax source (Thermo Scientific) was used for all ESI experiments. Figure 1 shows how the SAWN chip was interfaced to the mass spectrometer inlet. The area of the chip supporting the droplet was positioned 4-6 $\mathrm{mm}$ in front and under the capillary inlet and a droplet was deposited on the surface of the wafer (Figure 1b). To aerosolize the sample in the liquid droplet a waveform was applied to the IDT. The plume of aerosols formed was pulled into the mass spectrometer heated capillary inlet (Figure 1c) by local gas flow. For some experiments a silica capillary was placed right above the chip surface in front of the mass spectrometer inlet and the solution containing the sample was continuously supplied to the SAWN chip by means of a syringe pump. Electrode 3 was always grounded in this experiment as in Figure 1a. For the comparison experiments of ESI and SAWN, $3 \mu \mathrm{L} / \mathrm{min}$ flow rate was applied and three different API inlet capillary temperatures of $150{ }^{\circ} \mathrm{C}, 225^{\circ} \mathrm{C}$, and $300{ }^{\circ} \mathrm{C}$ were used. For the SAWN flow rate experiments, an $8 \mu \mathrm{L} / \mathrm{min}$ flow rate which is the highest flow rate sustainable under SAWN operation conditions was used to compare with the $3 \mu \mathrm{L} / \mathrm{min}$ results.

To mitigate the effect of instantaneous signal fluctuations, the data were averaged for $1 \mathrm{~min}$ for both the SAWN and ESI experiments. At least three replicates for each of the BzPy compounds was acquired and survival yield determined by averaging across all three replicates.

\section{Synthesis of Substituted Benzylpyridinium Salts}

Four substituted benzylpyridinium (BzPy) salts were prepared, which were 4-methoxy $(\mathrm{MeO})$, 4-methyl $(\mathrm{Me})$, 4-chloro $(\mathrm{Cl})$, and 4-nitro $\left(\mathrm{NO}_{2}\right)$. The substituted BzPy salts were synthesized following the reaction depicted in Scheme 1 [24]. All reagents and solvents used were obtained from Sigma-Aldrich Co. (St. Louis, MO, USA). Various benzyl chloride derivatives were mixed with a slight excess (1.2 molar equivalents) of pyridine in dry acetonitrile and stirred using a magnetic bar. Reactions were performed at room temperature overnight, except for 4-Cl BzPy where the reaction was carried out at $80^{\circ}$ $\mathrm{C}$ for $3 \mathrm{~h}$. At the end of the reaction time, diethyl ether was added to precipitate the BzPy salts. Solids were collected by filtration and dissolved in a water methanol mixture $(1: 1 \mathrm{vol} / \mathrm{vol})$ at $2 \mathrm{mg} / \mathrm{L}$.

\section{Survival Yield Calculations}

Historically, ion survival yield has been used to estimate ion internal energy imparted during ionization [16, 17, 20-25]. Survival yield methods measure the fraction of molecular ions having an internal energy below the dissociation threshold. Under the assumption that the time for the dissociation is long enough to exclude a kinetic shift ( $k t>>1$ for $E>E_{\mathrm{b}}$ ), it can be shown that this value also corresponds to the integral of the internal energy distribution function from zero to the energy barrier $E_{\mathrm{b}}$ Equation (1). In the following equation $S Y$ represents survival yield and $P(E)$ internal energy distribution.

$$
S Y=\int_{0}^{\mathrm{E}_{b}} P(E) d E
$$

Survival yield is obtained experimentally by measuring the ratio of the residual molecular ion intensity to the sum of intensities of the molecular ion and its fragment Equation (2).

$$
S Y=\frac{I\left(M^{+}\right)}{I\left(M^{+}\right)+I\left(F^{+}\right)}
$$

An S-shaped curve, $S Y(E)$, is fitted to the data and its first derivative is taken as the internal energy distribution function $P(E)$. $I$ represents the intensity of the ion of interest. In addition to the data acquired for the synthetic BzPy derivatives used here, four other data points were used as boundary conditions for curve fitting, with $-1 \mathrm{eV}, 0 \mathrm{eV}$, $0.1 \mathrm{eV}$ corresponding to $0 \%$ survival a yield and $5 \mathrm{eV}$ corresponding to $100 \%$ survival yield. When using the survival yield method, it is important to account for the contribution of all possible fragmentation channels. While BzPy ions mainly fragment by loss of pyridine, it has been reported that under certain conditions, a mass spectrum might contain other fragments [25]. To mitigate the effect in our calculations from non-pyridine fragmentation pathways, a sum of all detected fragment ion intensities [25] was used.<smiles>[R]c1ccc(CCl)cc1</smiles>

Scheme 1. Synthesis of a substituted benzylpyridinium salt 
Specifically, the fragment ions included for $\mathrm{MeO}-\mathrm{BzPy}$ were at $m / z 121,106,91$, and 77, those for Me-BzPy were at $\mathrm{m} / \mathrm{z}$ $105,103,79$, and 77, those for Cl-BzPy were at $\mathrm{m} / \mathrm{z} 125,99$, and 89 , and those for $\mathrm{NO}_{2}$-BzPy were at $m / z 136,169,106$, 90 , and 78. The corresponding survival yield of the four substituted BzPy ions were plotted versus their respective dissociation energies and the curve was fit to a sigmoidal function [16]. With the assumption that the intake of internal energy per vibrational mode is the same for all reactant ions under given experimental conditions, the derivative of the sigmoidal curve becomes an approximate internal energy distribution function of all precursor ions [16].

\section{Results and Discussion}

\section{Mass Spectra of Thermometer Ions}

Figure 2 shows the spectra of the 4-MeO BzPy derivatives obtained by SAWN and ESI at increasing temperatures in the mass spectrometer inlet capillary used to aid desolvation. At an inlet temperature of $150{ }^{\circ} \mathrm{C}$ (Figure 2a, b), 4-MeO
BzPy $(m / z 200)$ was the dominant peak with very little dissociation into 4-methoxybenzyl $(\mathrm{m} / \mathrm{z}$ 121). The average survival yield for the molecular ion was $95.3 \%$ for SAWN and $90.6 \%$ for ESI. However, increasing the temperature to $225{ }^{\circ} \mathrm{C}$ resulted in a noticeable increase of the 4-methoxybenzyl ion relative intensity, and the survival yield was reduced to $65.8 \%$ for SAWN and $45.3 \%$ for ESI (Figure 2c, d). Upon increasing the capillary inlet temperature to $300^{\circ}$ $\mathrm{C}$, the relative abundance of the molecular ion was further reduced, and the survival yield dropped to $21.1 \%$ for SAWN and $5.7 \%$ for ESI (Figure 2e, f). The survival yield was therefore easily determined for each thermometer ion using Equation (2). Measurements on the series of BzPy derivatives were extrapolated to determine the ion deposition energy. Not surprisingly, the data show that the temperature of the mass spectrometer inlet capillary used to aid desolvation played a large role in the internal energy deposition during the ionization process regardless of the ionization method used. Analysis of the temperature affects for 4-Me BzPy, 4-Cl BzPy, and 4- $\mathrm{NO}_{2}$ BzPy yielded similar spectra and results (see Supplementary Information).
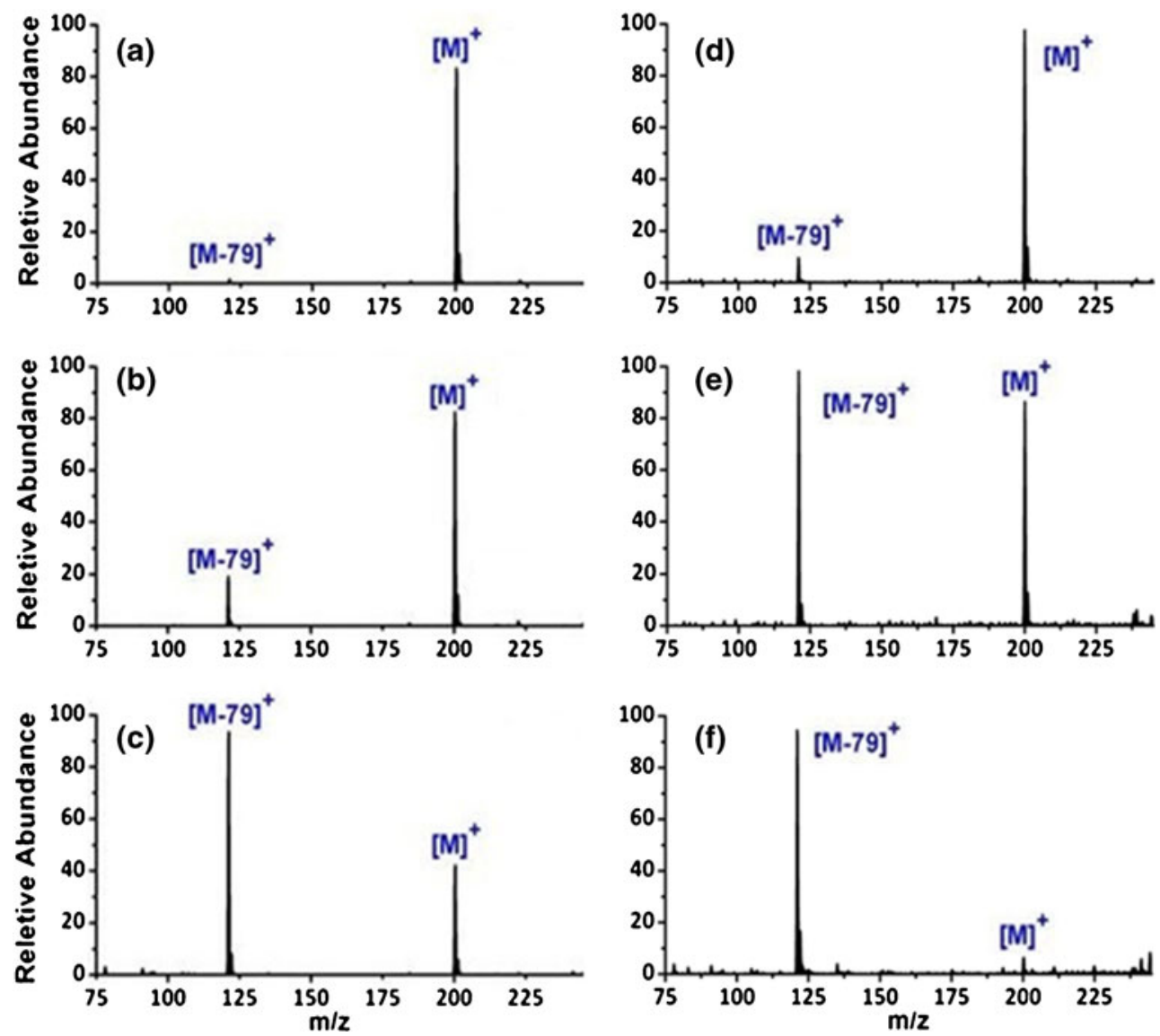

Figure 2. Mass spectra of 4-MeO benzylpyridinium ion and loss of pyridine. The molecular ion and a fragment ion are shown in each panel for the loss of pyridine as a neutral compound obtained by electrospray ionization (d), (e), (f) and surface acoustic wave nebulization (a), (b), (c) at increasing temperatures measured on the same capillary of an atmospheric pressure ionization inlet mass spectrometer at $150{ }^{\circ} \mathrm{C}$ (a), (d), $225^{\circ} \mathrm{C}$ (b), (e), and $300^{\circ} \mathrm{C}$ (c), (f) 


\section{Dissociation Energy Calculations}

The fragmentations of substituted BzPy ions are known to proceed via the mechanism described in Scheme 2. The precursor ion dissociates into a fragment ion (benzylium ion A or tropylium ion B) and a neutral pyridine molecule [18, $26,27]$. In order to derive ion internal energies from the measurements of ion survival yields, the dissociation energies for each BzPy ion are required. Several methods to calculate dissociation energies have been reported in the literature that gave different results, mainly due to the low level of theory used previously $[20,25,26]$. We reasoned that higher-level calculations at the "chemical accuracy limit" [28] should provide more accurate bond energies to be used as benchmarks for the evaluation of the experimental data, therefore also providing more accurate data fitting. Here we employed high-level computational methods including electron correlation as implemented in the Gaussian 03 suite of programs [29]. Optimized geometries were obtained by density functional theory calculations using Becke's hybrid functional (B3LYP) [30-32] and the 6-31+ $\mathrm{G}(\mathrm{d}, \mathrm{p})$ basis set. Stationary points were characterized by harmonic frequency calculations with B3LYP/6-31+G(d,p) as local minima with all real frequencies. The calculated frequencies were scaled with 0.963 and used to obtain zeropoint energy corrections for the dissociation energies. Improved energies were obtained by single-point calculations that were carried out with B3LYP and MP2(frozen core) using split-valence triple-basis sets of increasing size furnished with polarization and diffuse functions [e.g, 6-311++G(2 d,p), and $6-311++G(3 d f, 2 p)]$. Single point energies were also calculated with coupled-cluster theory [33] including single, double, and disconnected triple excitations [CCSD(T)] [34] and the 6$311 \mathrm{G}(\mathrm{d}, \mathrm{p})$ basis set. These were then expanded to effective $\operatorname{CCSD}(\mathrm{T}) / 6-311++\mathrm{G}(3 \mathrm{df}, 2 \mathrm{p})$ energies using the standard linear formula Equation (3):

$$
\begin{aligned}
& E[\operatorname{CCSD}(\mathrm{T}) / \text { large basis set }] \cong E[\operatorname{CCSD}(\mathrm{T}) / \text { small basis set }] \\
& +E[\mathrm{MP} 2 / \text { large basis set }]-E[\mathrm{MP} 2 / \text { small basis set }]
\end{aligned}
$$

The dissociation energies calculated as described above for 4-MeO, 4-Me, 4- $\mathrm{Cl}$, and 4- $\mathrm{NO}_{2}$ BzPy ions are summarized in Table 1. The $\operatorname{CCSD}(\mathrm{T})$ data showed dissociation energies for all benzylpyridinimum ions that were $0.4-0.5 \mathrm{eV}$ higher than those from B3LYP calculations (Table 1). Hence, the energy scale using these ions was recalibrated to comply with the high-level data. Benzylium and tropylium ions have the same $\mathrm{m} / \mathrm{z}$ values but different enthalpies of formation, which implies different threshold dissociation energies for the pertinent fragmentations. For the $\mathrm{Me}, \mathrm{Cl}$, and $\mathrm{NO}_{2}$ substituents, the tropylium ions were slightly more stable than their benzyl counterparts. The MeO-substituted benzyl and tropylium had comparable energies (Table 1). We used the lower of the calculated dissociation endothermicities to assess the energy thresholds in our internal energy calculations [16, 21-23].

\section{Survival Yields and Internal Ion Energies in ESI versus SAWN}

Figure 3a shows the survival yields obtained for SAWN and ESI produced ions under identical source conditions as a function of calculated dissociation energy. Data points correspond to the four BzPy derivatives: 4-MeO, 4-Me, 4$\mathrm{Cl}$, and 4-NO $\mathrm{N}_{2} \mathrm{BzPy}$ in order of increasing dissociation energy. Survival yield was plotted versus calculated bond dissociation energies in electron volts derived from Equation (3) for each substituted BzPy compound. The corresponding ion internal energy distributions were estimated by fitting a sigmoidal $S Y(E)$ function to the experimental data and taking the first derivative. Mean ion internal energies determined in two independent series of measurements are summarized in Table 2. As can be seen from Figure 3a, ions produced by SAWN clearly displayed higher survival yield and, hence, lower internal energy than their ESI formed counterparts, regardless of the substituent carried by the benzene ring. In fact, the mean internal energy deposited by ESI under these atmospheric ionization source conditions was over $30 \%$ higher than that of SAWN.

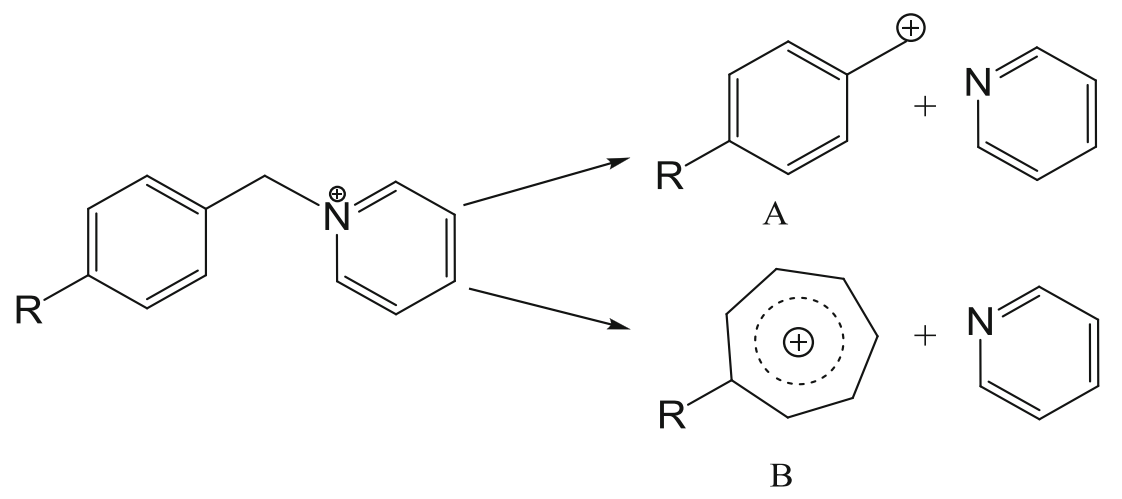

Scheme 2. Dissociation of BzPy ions into benzylium (a) or tropylium (b) ions 
Table 1. Calculated Bond Dissociation Energies for Substituted Benzylpyridinium Compounds

\begin{tabular}{lcccc}
\hline & \multicolumn{2}{c}{ B3LYP/6-31+G(d,p) (eV) } & \multicolumn{2}{c}{$\operatorname{CCSD}(\mathrm{T}) / 6-311++\mathrm{G}(3 \mathrm{df}, 2 \mathrm{p})(\mathrm{eV})$} \\
\cline { 2 - 5 } $\mathrm{R}$ & Benzylium & Tropylium & Benzylium & Tropylium \\
\hline $\mathrm{MeO}$ & 1.457 & 1.382 & $1.870^{\mathrm{a}}$ & 1.916 \\
$\mathrm{Me}$ & 1.808 & 1.575 & 2.303 & $2.139^{\mathrm{a}}$ \\
$\mathrm{Cl}$ & 1.947 & 1.756 & 2.407 & $2.301^{\mathrm{a}}$ \\
$\mathrm{NO}_{2}$ & 2.471 & 2.101 & 2.911 & $2.623^{\mathrm{a}}$ \\
\hline
\end{tabular}

${ }^{\mathrm{a}}$ Lowest energy path.

Two factors could be invoked to explain this difference. One explanation could be a difference in solvation between ions formed by both methods. Since the energy provided by the heated inlet capillary was the same for both ionization

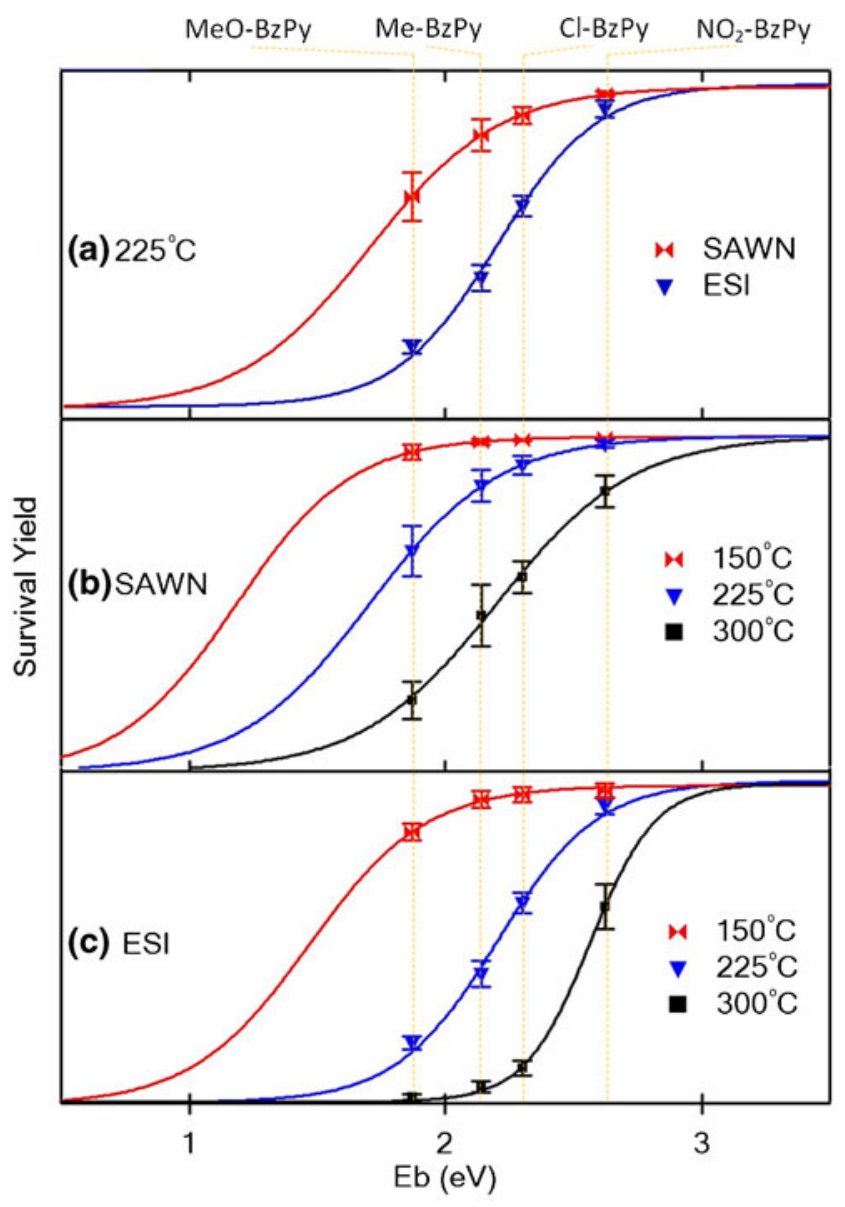

Figure 3. (a) Survival yield versus bond energy for four benzylpyridinium compounds obtained under identical atmospheric pressure ionization source conditions (i.e., inlet temperature $225^{\circ} \mathrm{C}$ ). (b) and (c) Effect of increasing the atmospheric pressure ionization inlet capillary temperatures on survival yields of substituted BzPy ions for surface acoustic wave nebulization [SAWN; (b)] and electrospray ionization [ESI; (c)]. The four BzPy ions used are $\mathrm{MeO}(\mathrm{A})$, Me (B), $\mathrm{Cl}(\mathrm{C})$, and $\mathrm{NO}_{2}-\mathrm{BzPy}(\mathrm{D})$
Table 2. Mean Internal Energy Deposited during Surface Acoustic Wave Nebulization (SAWN) and Electrospray Ionization (ESI) at Increasing Capillary Inlet Temperatures

\begin{tabular}{lcc}
\hline Temperature & $\mathrm{E}_{\text {int }}$ SAWN $(\mathrm{eV})$ & $\mathrm{E}_{\text {int }}$ ESI $(\mathrm{eV})$ \\
\hline $150^{\circ} \mathrm{C}$ & $1.23 \pm 0.02$ & $1.29 \pm 0.01$ \\
$225^{\circ} \mathrm{C}$ & $1.49 \pm 0.05$ & $1.96 \pm 0.02$ \\
$300^{\circ} \mathrm{C}$ & $2.17 \pm 0.04$ & $2.44 \pm 0.01$ \\
\hline
\end{tabular}

methods, more solvated ions would experience more evaporative cooling. Consequently, less energy would be transferred to the analyte, preserving more of the precursor ion. For ESI, previous studies had indicated the droplet size to be in the range of 1 to $20 \mu \mathrm{m}[35,36]$. In support of this explanation, pilot experiments using the same solvent conditions and SAWN chips as used here (Langridge-Smith personal communication) have indicated that depending on the SAWN experimental parameters (i.e., frequency, amplitude), droplets produced by SAWN range from 1 to $1000 \mu \mathrm{m}$ with most being similar to ESI [37]. However, there is also a substantial contribution from droplets that are 10-100 times larger than ESI produced droplets, which has been observed under different experimental conditions [38, 39].

Another reason for the lower internal energies of SAWNproduced ions may be related to the absence of high electric field in the SAWN process and the low charge density of the SAWN aerosols. Regarding the charge density, our preliminary measurements with model analytes indicated lower ion currents generated by SAWN than by electrospray. Combined with larger droplets, the lower total charge indicates that the SAWN-produced droplets have lower charge densities than those formed by electrospray. Thus, the SAWN droplets undergo more solvent evaporation before reaching the Rayleigh limit for fission and ion desorption on the gas phase, forming cooler ions. Additionally, in the high voltage gradient between the ESI tip and the inlet capillary, the ESI formed droplets experience acceleration and many collisions with the ambient gas. In ESI the speed of the droplet would be a combination of the acceleration from the electric field and the thermal velocity. While the thermal velocity of a common ESI droplet [40] is relatively low $(10 \mathrm{~mm} / \mathrm{s})$, the ESI electric field provides substantial acceleration. Comparison of the typical travel time of an ESI droplet $(<1 \mathrm{~ms})$ [41] with that of a SAWN droplet (50$100 \mathrm{~ms}$ ) clearly indicates that the latter move more slowly and, thus, the kinetic energy of droplets entering the capillary inlet is likely to be lower from SAWN than ESI, which contributes to the observed ion internal energy effect. Therefore, it is likely that a combination of larger SAWN droplets, lower charge density, and less kinetic energy contributes to higher ion survival yields in SAWN compared with ESI. While the exact mechanism is still unclear, these results suggest that SAWN could be an attractive alternative to ESI for the analysis of thermally or chemically labile molecules. 


\section{Effect of Inlet Capillary Temperature on Survival Yield}

When estimating bond dissociation energies from atmospheric pressure ionization (API) using an empirical method such as survival yield method, several API parameters have been shown to influence ion dissociation [16]. In the API configuration used here, droplets entered a heated inlet capillary that assisted solvent vaporization and ion desolvation. The surviving solvent-free ions were then detected by the mass analyzer. In the present study, to avoid introduction of artificial differences in measured ion survival yields between ESI and SAWN, all mass spectrometer parameters were nominally identical for both API methods. To further investigate the effect of desolvation on internal energies, three inlet capillary temperatures were examined. As shown in Figure 3b, c, and Table 2, the temperature of the inlet capillary of the mass spectrometer had a dramatic effect on the survival yield and the calculated mean ion internal energy from both SAWN and ESI. At the lowest temperature tested $\left(150{ }^{\circ} \mathrm{C}\right)$, the internal energy difference between SAWN and ESI was quite modest $(0.06 \mathrm{eV})$. As the temperature increased, the difference in deposited energy between ESI and SAWN became much more significant. Overall, SAWN displayed higher survival yields than ESI over the whole range of temperatures tested, and the greatest difference $(0.47 \mathrm{eV})$ was observed at $225^{\circ} \mathrm{C}$.

The internal energy the ions receive depends on the heat input from the hot desolvation gas and the heat loss by solvent evaporation from the droplet and ion desolvation after droplet fission. Therefore, presuming that the last stages of ion desolvation are similar for ESI and SAWN-produced droplets, one would expect that ions originating from larger droplets would receive less energy during the API process than ions originating from smaller droplets. Our experimental results are therefore consistent with the hypothesis that SAWN produced droplets are larger than those produced by ESI and thus produce ions of a relatively lower internal energy.

\section{Effect of Flow Rate on Survival Yield}

In the same way as direct infusion by ESI, SAWN experiments were conducted using a continuous deposition of liquid on the chip. This allowed the relationship between internal energy distribution and flow rate to be studied under varying inlet capillary temperatures [17, 22]. Results from a series of such measurements are summarized in Table 3 . We

Table 3. Calculated Internal Energies $\left(E_{\text {int }}\right)$ for Surface Acoustic Wave Nebulization at Different Flow Rates and Temperatures

\begin{tabular}{lll}
\hline Temperature & $\mathrm{E}_{\text {int }}(\mathrm{eV})^{\mathrm{a}}$ & $\mathrm{E}_{\text {int }}(\mathrm{eV})^{\mathrm{b}}$ \\
\hline $150^{\circ} \mathrm{C}$ & $1.23 \pm 0.01$ & $1.18 \pm 0.02$ \\
$225^{\circ} \mathrm{C}$ & $1.49 \pm 0.05$ & $1.32 \pm 0.06$ \\
$300^{\circ} \mathrm{C}$ & $2.17 \pm 0.04$ & $2.06 \pm 0.03$ \\
\hline
\end{tabular}

\footnotetext{
${ }^{\text {a }}$ At a $3 \mu \mathrm{L} / \mathrm{min}$ flow rate.
}

${ }^{b}$ At a $8 \mu \mathrm{L} / \mathrm{min}$ flow rate. observed an increase in the survival yield for all four BzPy ions when increasing the flow rate from $3 \mu \mathrm{L} / \mathrm{min}$ to $8 \mu \mathrm{L} /$ min, the highest flow rate that could be used while still maintaining the nebulization process. However, this effect was less pronounced than the temperature effect, or the difference between SAWN and ESI. Overall, under all tested temperatures, less fragmentation occurred during the ionization process when the sample flow rate was set at $8 \mu \mathrm{L} / \mathrm{min}$. This could be explained by the fact that the larger quantity of liquid brought onto the surface of the chip per unit time influenced the size distribution of the nebulized droplets or possibly increased the number of droplets formed in a certain period of time. Regardless, this increase in flow rate resulted in a requirement of more energy to evaporate the solvent and generate ions, which in turn led to higher survival yield. Thus, the increase in precursor ion survival yield for all four BzPy ions resulted in an even lower internal energy distribution at the higher flow rate. Again, these results are consistent with the hypothesis that larger droplets (or more droplets) affect the energy distribution of SAWN.

\section{Conclusions}

We have investigated the energetics of SAWN-generated precursor ions and compared these results to ESI under identical API source conditions using a common ion survival yield method with a series of four substituted BzPy ions. The results clearly showed that the survival yield of SAWNgenerated ions was indeed higher than those of ESI, suggesting SAWN is a "softer" ionization process. In fact, under all conditions tested, SAWN-generated ions had a higher survival yield than those formed by ESI. We also noted that the difference between SAWN and ESI was more pronounced at higher inlet capillary temperature. This suggests that either the SAWN-generated droplets required more energy for desolvation or that the ESI-generated droplets experienced a higher rate of desolvation due to the additional voltage differential they experience from the voltage applied for ESI. Another parameter that could contribute to the difference is droplet size because it is likely that the SAWN-generated droplets are larger on average than those from ESI. The internal energy distribution of BzPy ions was also affected by sample flow rate, but to a lesser extent. This could be explained by the difference in the amount of droplets entering the inlet capillary or by an increase in droplet size resulting from the use of higher flow rates. Finally, and interestingly for those studying ions susceptible to fragmentation by currently available methods, we can estimate that SAWN may impart the least energy of all commercially available API methods. For example, while a direct comparison of internal energy distribution of SAWN with other ambient ionization source has not been conducted here, previous results have been reported for DART and DESI using the same BzPy ions series. From these studies, it was shown that DESI [22] produced similar ion internal 
energy distributions to ESI and the mean internal energy of DESI was $10 \%$ higher than ESI. Additionally, DART was compared with ESI and shown to produce slightly lower ion survival yields (between $25 \%$ to $36 \%$ depending on conditions) [23]. Given our results showing that SAWN, depending on the conditions used, deposits around $4 \%$ to $23 \%$ less internal energy than ESI, we can conservatively estimate that SAWN is "softer" than both DESI and DART. Due to the many operational parameters of SAWN that are just beginning to be understood, such as sample flow rate, amplitude, and frequency of the acoustic wave, these encouraging results require further investigation.

\section{Acknowledgments}

The authors thank the National Institutes of Health grant 1U54 AI57141-01 (D.R.G.) for funding and support. The Department of Chemistry Computational Center has been supported jointly by the NSF (grants CHE-0342956 and CHE-1055132 to F.T.) and University of Washington. C.D.M. was awarded a CEA-Eurotalent outgoing fellowship (grant PCOFUND-GA-2008-228664) to work at the University of Washington during the course of these experiments. Additional thanks are due to the University of Washington, School of Pharmacy Mass Spectrometry Facility and University of Washington, School of Medicine Proteomics Resource (UWPR95794). Part of this work was conducted at the University of Washington NanoTech User Facility, a member of the National Science Foundation's National Nanotechnology Infrastructure Network (NNIN). The authors also thank Dr. P. R. R. Langridge-Smith of the School of Chemistry at the University of Edinburgh for sharing the data on SAW produced droplet size measured with a Malvern Spraytec device.

\section{References}

1. Fenn, J.B., Mann, M., Meng, C.K., Wong, S.F., Whitehouse, C.M.: Electrospray ionization for mass-spectrometry of large biomolecules. Science 246(4926), 64-71 (1989)

2. Karas, M., Hillenkamp, F.: Laser desorption ionization of proteins with molecular masses exceeding 10000 Daltons. Anal. Chem. 60(20), 22992301 (1988)

3. Tanaka, K., Waki, H., Ido, Y., Akita, S., Yoshida, Y., Yoshida, T., Matsuo, T.: Protein and polymer analyses up to $\mathrm{m} / \mathrm{z} 100,000$ by laser ionization time-of-flight mass spectrometry. Rapid Commun. Mass Spectrom. 2(8), 151-153 (1988)

4. Aebersold, R., Mann, M.: Mass spectrometry-based proteomics. Nature 422(6928), 198-207 (2003)

5. Singh, P., Shaffer, S.A., Scherl, A., Holman, C., Pfuetzner, R.A., Freeman, T.J.L., Miller, S.I., Hernandez, P., Appel, R.D., Goodlett, D.R.: Characterization of protein cross-links via mass spectrometry and an openmodification search strategy. Anal. Chem. 80(22), 8799-8806 (2008)

6. Bolbach, G.: Matrix-assisted laser desorption/ionization analysis of noncovalent complexes: fundamentals and applications. Curr. Pharm. Des. 11(20), 2535-2557 (2005)

7. Loo, J.A.: Studying, noncovalent protein complexes by electrospray ionization mass spectrometry. Mass Spectrom. Rev. 16(1), 1-23 (1997)

8. Veenstra, T.D.: Electrospray ionization mass spectrometry: a promising new technique in the study of protein/DNA noncovalent complexes. Biochem. Biophys. Res. Commun. 257(1), 1-5 (1999)
9. Alvarez, M., Friend, J., Yeo, L.Y.: Rapid generation of protein aerosols and nanoparticles via surface acoustic wave atomization. Nanotechnology 19(455103) (2008)

10. Franke, T.A., Wixforth, A.: Microfluidics for miniaturized laboratories on a chip. Chem. Phys. Chem. 9(15), 2140-2156 (2008)

11. Friend, J.R., Yeo, L.Y., Arifin, D.R., Mechler, A.: Evaporative selfassembly assisted synthesis of polymeric nanoparticles by surface acoustic wave atomization. Nanotechnology 19(14), 145301-145307 (2008)

12. Lange, K., Rapp, B.E., Rapp, M.: Surface acoustic wave biosensors: a review. Anal. Bioanal. Chem. 391(5), 1509-1519 (2008)

13. Heron, S.R., Wilson, R., Shaffer, S.A., Goodlett, D.R., Cooper, J.M.: Surface acoustic wave nebulization of peptides as a microfluidic interface for mass spectrometry. Anal. Chem. 82(10), 3985-3989 (2010)

14. Ho, J., Tan, M.K., Go, D.B., Yeo, L.Y., Friend, J.R., Chang, H.C.: Paper-based microfluidic surface acoustic wave sample delivery and ionization source for rapid and sensitive ambient mass spectrometry. Anal. Chem. 83(9), 3260-3266 (2011)

15. Harris, G.A., Galhena, A.S., Fernandez, F.M.: Ambient sampling/ ionization mass spectrometry: applications and current trends. Anal. Chem. 83(12), 4508-4538 (2011)

16. Collette, C., Drahos, L., De Pauw, E., Vekey, K.: Comparison of the internal energy distributions of ions produced by different electrospray sources. Rapid Commun. Mass Spectrom. 12(22), 1673-1678 (1998)

17. Collette, C., De Pauw, E.: Calibration of the internal energy distribution of ions produced by electrospray. Rapid Commun. Mass Spectrom. 12 (4), 165-170 (1998)

18. Zins, E.L., Pepe, C., Schroder, D.: Energy-dependent dissociation of benzylpyridinium ions in an ion-trap mass spectrometer. J. Mass Spectrom. 45(11), 1253-1260 (2010)

19. Greisch, J.F., Gabelica, V., Remacle, F., De Pauw, E.: Thermometer ions for matrix-enhanced laser desorption/ionization internal energy calibration. Rapid Commun. Mass Spectrom. 17(16), 1847-1854 (2003)

20. Luo, G.H., Marginean, I., Vertes, A.: Internal energy of ions generated by matrix-assisted laser desorption/ionization. Anal. Chem. 74(24), 6185-6190 (2002)

21. Naban-Maillet, J., Lesage, D., Bossee, A., Gimbert, Y., Sztaray, J., Vekey, K., Tabet, J.C.: Internal energy distribution in electrospray ionization. J. Mass Spectrom. 40(1), 1-8 (2005)

22. Nefliu, M., Smith, J.N., Venter, A., Cooks, R.G.: Internal energy distributions in desorption electrospray ionization (DESI). J. Am. Soc. Mass Spectrom. 19(3), 420-427 (2008)

23. Harris, G.A., Hostetler, D.M., Hampton, C.Y., Fernandez, F.M.: Comparison of the internal energy deposition of direct analysis in real time and electrospray ionization time-of-flight mass spectrometry. $J$. Am. Soc. Mass Spectrom 21(5), 855-863 (2010)

24. Dagan, S., Hua, Y.M., Boday, D.J., Somogyi, A., Wysocki, R.J., Wysocki, V.H.: Internal energy deposition with silicon nanoparticleassisted laser desorption/ionization (SPALDI) mass spectrometry. Int. J. Mass Spectrom. 283(1/3), 200-205 (2009)

25. Barylyuk, K.V., Chingin, K., Balabin, R.M., Zenobi, R.: Fragmentation of benzylpyridinium "thermometer" ions and its effect on the accuracy of internal energy calibration. J. Am. Soc. Mass Spectrom. 21(1), 172177 (2010)

26. Zins, E.L., Pepe, C., Rondeau, D., Rochut, S., Galland, N., Tabet, J.C.: Theoretical and experimental study of tropylium formation from substituted benzylpyridinium species. J. Mass Spectrom. 44(1), 12-17 (2009)

27. Zins, E.L., Rondeau, D., Karoyan, P., Fosse, C., Rochut, S., Pepe, C.: Investigations of the fragmentation pathways of benzylpyridinium ions under ESI/MS conditions. J. Mass Spectrom. 44(12), 1668-1675 (2009)

28. Curtiss, L.A., Raghavachari, K., Trucks, G.W., Pople, J.A.: Gaussain-2 theory for molecular energies of foirst and second-row compounds. $J$. Chem. Phys. 94, 7221-7230 (1991)

29. Frisch, M.J., Trucks, G.W., Schlegel, H.B., Scuseria, G.E., Robb, M.A., Cheeseman, J.R., Montgomery Jr., J.A., Vreven, T., Kudin, K.N., Burant, J.C., Millam, J.M., Iyengar, S.S., Tomasi, J., Barone, V., Mennucci, B., Cossi, M., Scalmani, G., Rega, N., Petersson, G.A., Nakatsuji, H., Hada, M., Ehara, M., Toyota, K., Fukuda, R., Hasegawa, J., Ishida, M., Nakajima, T., Honda, Y., Kitao, O., Nakai, H., Klene, M., Li, X., Knox, J.E., Hratchian, H.P., Cross, J.B., Bakken, V., Adamo, C., Jaramillo, J., Gomperts, R., Stratmann, R.E., Yazyev, O., Austin, A.J., Cammi, R., Pomelli, C., Ochterski, J.W., Ayala, P.Y., Morokuma, K., Voth, G.A., Salvador, P., Dannenberg, J.J., Zakrzewski, V.G., 
Dapprich, S., Daniels, A.D., Strain, M.C., Farkas, O., Malick, D.K., Rabuck, A.D., Raghavachari, K., Foresman, J.B., Ortiz, J.V., Cui, Q., Baboul, A.G., Clifford, S., Cioslowski, J., Stefanov, B.B., Liu, G., Liashenko, A., Piskorz, P., Komaromi, I., Martin, R.L., Fox, D.J., Keith, T., Al-Laham, M.A., Peng, C.Y., Nanayakkara, A., Challacombe, M., Gill, P.M.W., Johnson, B., Chen, W., Wong, M.W., Gonzalez, C., Pople, J.A.: Gaussian 03, Revision B. 05. Gaussian, Inc, Pittsburgh PA (2003)

30. Becke, A.D.: A new mixing of hartree-fock and local density-functional theories. J. Chem. Phys. 98(2), 1372-1377 (1993)

31. Becke, A.D.: Density-functional thermochemistry. 3. The role of exact exchange. J. Chem. Phys. 98(7), 5648-5652 (1993)

32. Stephens, P.J., Devlin, F.J., Chabalowski, C.F., Frisch, M.J.: Ab-initio calculation of vibrational absorption and circular-dichroism spectra using density-functional force-fields. J. Phys. Chem. 98(45), 1162311627 (1994)

33. Čížek, J., Paldus, J., Šroubková, L.: Cluster expansion analysis for delocalized systems. Int. J. Quantum Chem. 3(2), 149-167 (1969)

34. Purvis, G.D., Bartlett, R.J.: A full coupled-cluster singles and doubles model - the inclusion of disconnected triples. J. Chem. Phys. 76(4), 1910-1918 (1982)
35. Smith, J.N., Flagan, R.C., Beauchamp, J.L.: Droplet evaporation and discharge dynamics in electrospray ionization. J. Phys. Chem. A 106 (42), 9957-9967 (2002)

36. Wortmann, A., Kistler-Momotova, A., Zenobi, R., Heine, M., Wilhelm, O., Pratsinis, S.: Shrinking droplets in electrospray ionization and their influence on chemical equilibria. J. Am. Soc. Mass Spectrom. 18(3), 385-393 (2007)

37. Juraschek, R., Dulcks, T., Karas, M.: Nanoelectrospray-more than just a minimized-flow electrospray ionization source. J. Am. Soc. Mass Spectrom. 10(4), 300-308 (1999)

38. Qi, A., Friend, J.R., Yeo, L.Y., Morton, D.A.V., McIntosh, M.P., Spiccia, L.: Miniature inhalation therapy platform using surface acoustic wave microfluidic atomization. Lab on a Chip 9(15), 2184-2193 (2009)

39. Qi, A., Yeo, L.Y.; Friend, J.R.: Interfacial destabilization and atomization driven by surface acoustic waves. Phys. Fluids 20, 074103-074117 (2008)

40. Kebarle, P.: A brief overview of the present status of the mechanisms involved in electrospray mass spectrometry. J. Mass Spectrom. 35(7), 804-817 (2000)

41. Kebarle, P.; Tang, L.: From ions in solution to ions in the gas phasethe mechanism of electrospray mass spectrometry. Anal. Chem. 65(22), 972A-986A (1993) 